\title{
ИЗУЧЕНИЕ ОРГАНИЧЕСКОГО ВЕЩЕСТВА ГОРЮЧЕГО СЛАНЦА МЕСТОРОЖДЕНИЯ «МАНДРА» НИЗКОТЕМПЕРАТУРНОЙ ДЕСТРУКТИВНОЙ ГИДРОГЕНИЗАЦИЕЙ
}

Болгарские сланцы геологически принадлежат главным образом к эоцено-олигоценовой формации. По месторождению «Мандра» установлены 4 пласта мощностью от 0,5 до $17,0 \mathrm{M}$. Генетически они представляют собой самостоятельную толщу, образовавшуюся в небольшом сравнительно спокойном море или заливе, которые покрывали эти земли в третичной эпохе.

В данной работе деструктивной гидрогенизацией исследовалось органическое вещество (OB) болгарского горючего сланца Мандраского месторождения.

\section{Методика}

В опытах использовался измельченный сланец, который после предварительной обработки $10 \%$-ной соляной кислотой и экстракции хлороформом (количество извлеченного битумоида $1,6 \%$ от ОВ) имел следующие показатели, \%: W 1,$9 ; \mathrm{A} 64,3 ; \mathrm{CO}_{2}$ 0,3. Элементный состав ОВ, \%: С 74,9; Н 11,2; N 1,8; O+S 12,1. После обработки содержание ОВ повышалось от 24,0 до $33,5 \%$. Гидрогенизация проводилась в качающемся автоклаве емкостью 2 л. Время гидрогенизации составляло во всех опытах 6 ч. Количество сланца -250 г $(84,0$ г ОВ). Катализатор (молибдат аммония) наносился на измельченный сланец последовательной пропиткой его раствором из расчета $1 \%$ молибдена на ОВ. Однократная каталитическая гидрогенизация проводилась при температурах 330 , 360,390 и $420^{\circ} \mathrm{C}$ (начальное давление водорода 50 ат): Ступенчатая каталитическая гидрогенизация выполнялась в три приема: $360^{\circ} / 25$ aт, $360^{\circ} / 50$ aт и $390^{\circ} / 50$ aт.

Известно, что процессы передачи водорода проходят более активно в жидкой фазе, поэтому гидрогенизация проводилась при $370^{\circ}$ в присутствии воды и формиата натрия. Соотношение сланец-вода-формиат $2: 2: 1$. Формиат в водной среде разлагается по реакции

$$
\mathrm{HCOONa}+\mathrm{HOH} \rightarrow \mathrm{NaOH}+\mathrm{CO}_{2}+\mathrm{H}_{2}
$$

Образующийся водород вступает в реакцию с керогеном. Для сравнения проводились также термическое растворение в присутствии органического растворителя циклогексана и конверсия водой при $370^{\circ}$; соотношение сланец-циклогексан (вода) $1: 2$.

Смола полукоксования сланца была получена в лабораторной реторте по стандартному режиму (ГОСТ 3168-66).

Гидрогенизаты отделялись от твердого остатка фильтрованием, для полного отделения жидкого продукта твердый остаток дополнительно экстрагировался бензолом. В опытах, проводимых без растворителя, образующийся жидкий гидрогенизат адсорбировался на твердом остатке и мог быть выделен лишь экстрагированием бензолом. 
Полученные гидрогенизаты, а также смола полукоксования разделялись на групповые компоненты методом тонкослойной хроматографии на силикагеле Л 40/100 мкм, элюент $н$-гексан [']. Разделенные фракции, как и исходные смеси, анализировались газохроматографически на анализаторе Хром-4 с пламенно-ионизационным детектором, газ-носитель - гелий. Характеристика применявшихся колонок: 1) $2 \%$ дексила 300 на хроматоне $N$-AW $D M C S ; 2,2 \mu \times 1,8$ мм; 2) $4 \%$ силиконового эластомера Е 301 на инертоне $A W D M C S ; 3,7 \mu \times 3,0 м \mu ; 3) 15 \%$ апьезона $L$ на хроматоне $N A W ; 6,0 \mu \times$ $1,5 \mathrm{sm}$.

Компонентный состав газа исследовался на хроматографе УХ-2 (детектор-катарометр); первая колонка $1,0 \mu \times 4$ м.м, насадка - молекулярные сита СаА $0,20-0,25$ м.м; вторая колонка 10 м 4 мм, носитель - хезасорб $(0,25-0,36$ мм) с 10\% сквалана [²].

Для жидких продуктов определились также показатель преломления, удельный вес, молекулярная масса и элементный состав. Фенолы выделялись $10 \%$-ным раствором гидроокиси натрия. Инфракрасные спектры гидрогенизатов и твердых остатков снимались на спектрофотометре UR-10 в таблетках из $\mathrm{KBr}$.

\section{Обсуждение результатов}

Данные о выходе продуктов гидрогенизации приводятся в табл. 1: выходы жидкого гидрогенизата относительно низкие - от 6,3 до $17,8 \%$ от количества сланца, особенно при каталитической гидрогенизации до $370^{\circ}$. При одноступенчатой гидрогенизации только при температуре $390-420^{\circ}$ достигаются такие же выходы смолы, как при полукоксовании. В выбранных условиях (без растворителя и при низкой температуре) деструкция проходит медленно, при ступенчатой гидрогенизации на каждой ступени образуются почти равные количества гидрогенизата, сумма которых превышает выход при полукоксовании. В присутствии органического растворителя, а также воды увеличивается выход жидкого продукта. Образующиеся гидрогенизаты (табл. 1) имеют близкий групповой состав, близки также их другие показатели. Молекулярная масса жидкого продукта высокая, наиболее высокой молекулярной массой отличается гидрогенизат, полученный при самой низкой температуре $-330^{\circ}$. Групповой состав показывает, что на неароматические углеводороды приходится $1 / 3$ всего жидкого продукта. Таким же высоким содержанием алифатических углеводородов отличается смола полукоксования, но доля нейтральных кислородных соединений в ней меньше, чем в гидрогенизатах. Хроматограммы суммарных гидрогенизатов свидетельствуют о том, что самыми характерными структурными элементами керогена мандраского сланца и соответственно смолы деструкции являются длинные неразветвленные углеродные цепи. Углеродные цепи керогена содержат от 10 до 37 атомов углерода. По данным одно- и трехступенчатой гидрогенизации, основная часть цепей содержит от 20 до 30 атомов углерода. В мягких условиях на первой стадии разложения отщепляются более длинные парафиновые цепи, а цепи $\mathrm{C}_{13}-\mathrm{C}_{21}-$ в конце деструкции (рис. $1-3$ ). В смоле полукоксования болгарского сланца, как обычно в продуктах термической деструкции, содержатся и $\boldsymbol{H}$-алкены.

Состав ароматической части гидрогенизатов намного проще, чем при гидрогенизации керогена кукерсита: присутствуют тетралин, нафталин, метилнафталины, диметилнафталины, аценафтен, флуорен, фенантрен, антрацен и др. Во фракциях нейтральных кислородных соединений жидкого продукта термического растворения, конверсии с водой и гидрогенизации с формиатом обнаружены длинноцепочечные $\boldsymbol{H}$-алканоны от $\mathrm{C}_{9}$ 


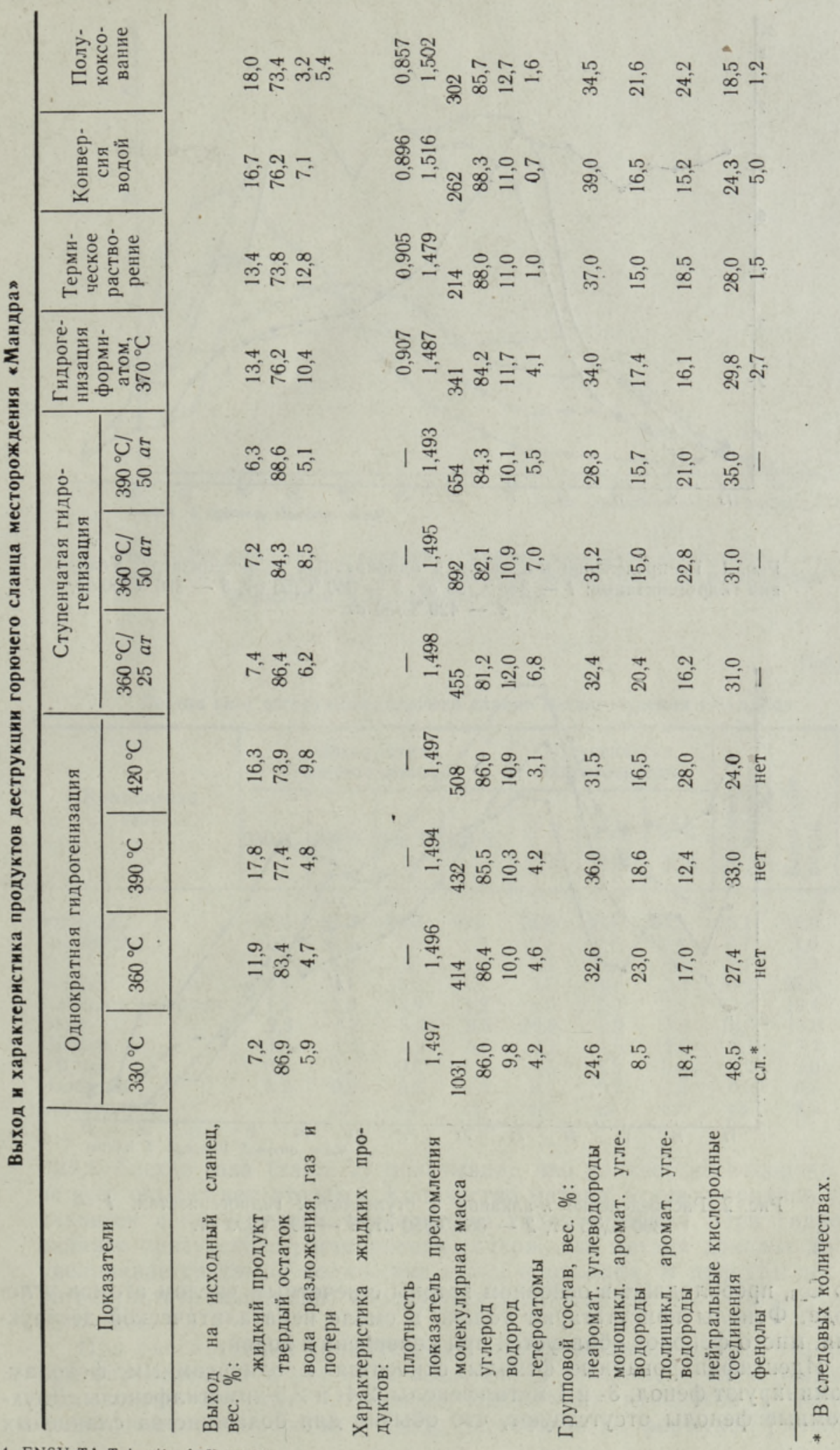

4 ENSV TA Toimetised. K 31979 


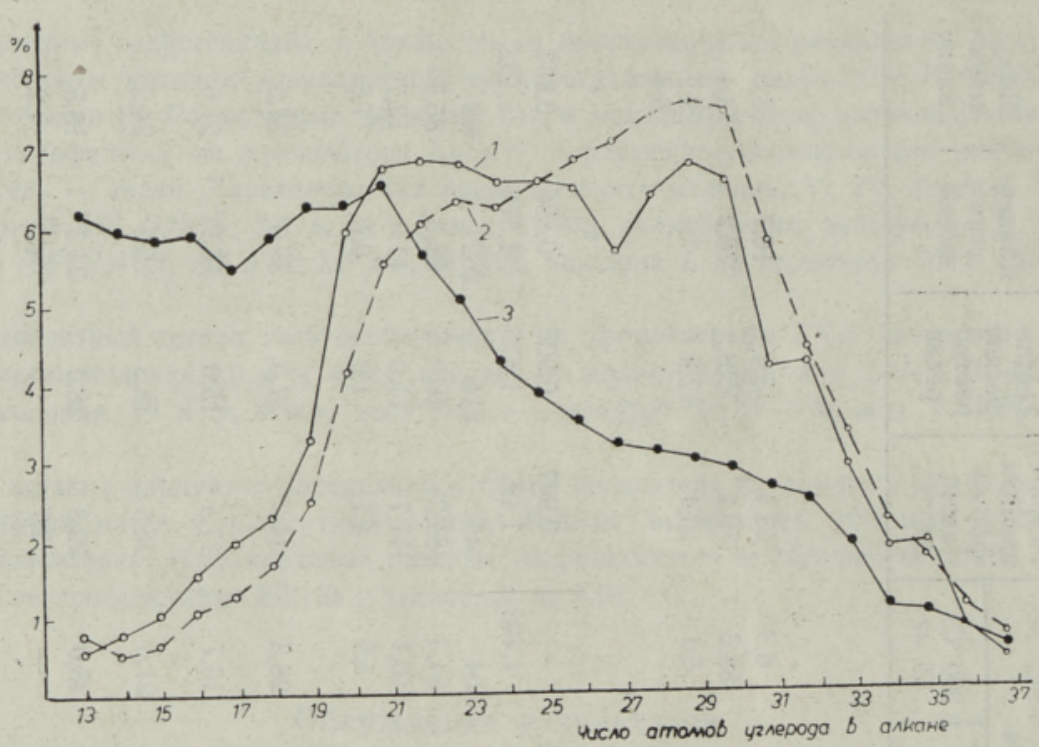

Рис. 1. Распределение $\boldsymbol{H}$-алканов в однократных гидрогенизатах. Условия гидрогенизации: $1-330^{\circ} \mathrm{C} / 50 a t, 2-360^{\circ} \mathrm{C} / 50 a t, 3-390^{\circ} \mathrm{C} / 50 a T$, $4-420^{\circ} \mathrm{C} / 50$ at.

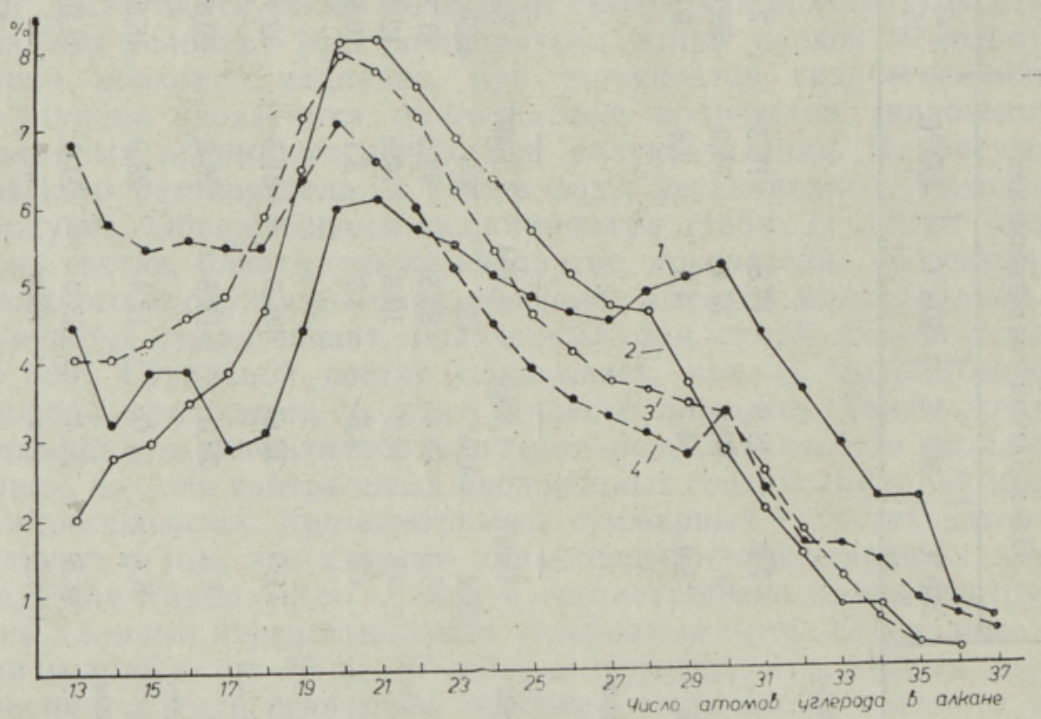

Рис. 2. Распределение $\boldsymbol{H}$-алканов в ступенчатых гидрогенизатах. 1 $360^{\circ} \mathrm{C} / 25$ ar, $2-360^{\circ} \mathrm{C} / 50$ aт, $3-390^{\circ} \mathrm{C} / 50$ ar.

до $\mathrm{C}_{23}$, преобладают в основном кетоны с нечетным числом атомов углерода. Фенолы присутствуют только в смоле некаталитической деструкции, много фенолов образуется при конверсии с водой.

Идентифицированные фенолы относятся к одноатомным фенолам. Доминируют фенол, 3- и 4-метилфенолы, 2,4- и 2,5-диметилфенолы. Двухатомные фенолы отсутствуют, что обычно для большинства сланцевых 


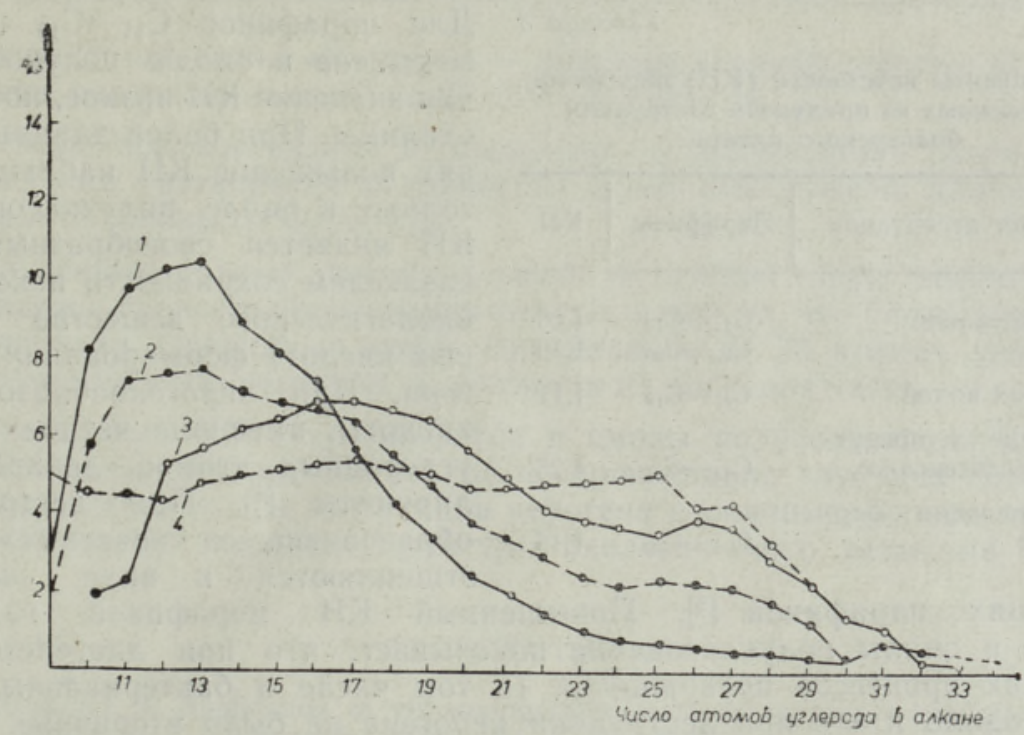

Рис. 3. Распределение $н$-алканов в жидких продуктах деструкции. 1 термическое растворение, 2 - конверсия водой, 3 - гидрогенизация формиатом, 4 - полукоксование.

Таблица 2

Состав газа деструкции горючего сланца месторождения «Мандра»

\begin{tabular}{|c|c|c|c|c|c|c|c|c|c|c|}
\hline \multirow{2}{*}{$\begin{array}{l}\text { Компоненты } \\
\text { газа }\end{array}$} & \multicolumn{4}{|c|}{$\begin{array}{c}\text { Однократная } \\
\text { гидрогенизация }\end{array}$} & \multicolumn{3}{|c|}{$\begin{array}{c}\text { Ступенчатая } \\
\text { гидрогенизация }\end{array}$} & \multirow{2}{*}{ 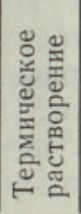 } & \multirow{2}{*}{ 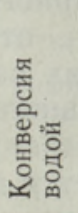 } & \multirow{2}{*}{ 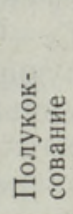 } \\
\hline & $330^{\circ} \mathrm{C}$ & $360^{\circ} \mathrm{C}$ & $390^{\circ} \mathrm{C}$ & $420^{\circ} \mathrm{C}$ & 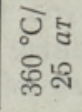 & $\begin{array}{l}\overline{0} \\
0 \\
\text { ॄิ }\end{array}$ & $\begin{array}{l}\overline{0} \\
\text { 용ㅇ }\end{array}$ & & & \\
\hline Водород & 85,0 & 87,2 & 80,0 & 62,1 & 74,0 & 86,6 & 84,5 & 35,1 & 16,9 & 50,9 \\
\hline Кислород & 1,7 & 1,3 & 1,2 & 1,3 & 1,1 & 0,5 & 0,4 & 0,7 & 1,6 & 0,7 \\
\hline Азот & 1,5 & 4,0 & 3,0 & 4,1 & 1,6 & 1,0 & 2,0 & 2,1 & 7,3 & 2,0 \\
\hline Метан & 6,3 & 3,1 & 8,6 & 14,7 & 3,7 & 4,5 & 3,9 & 20,9 & 22,8 & 22,2 \\
\hline Двуокись углерода & 1,2 & 1,3 & 0,9 & 1,2 & 4,5 & 2,6 & 1,4 & 13,8 & 19,4 & 4,3 \\
\hline Этан & 2,3 & 1,2 & 3,2 & 9,5 & 10,8 & 2,6 & 3,8 & 16,9 & 13,0 & 10,8 \\
\hline Пропан & 1,4 & 1,2 & 2,2 & 5,6 & 2,1 & 1,5 & 2,5 & 8,1 & 7 & 6,6 \\
\hline$\mu$-Бутан & 0,4 & 0,5 & 0,6 & 1,1 & 1,5 & 0,5 & 0,3 & 2,2 & 2, & 2,3 \\
\hline Изобутан & 0,2 & 0,2 & 0,3 & 0,4 & 0,7 & 0,2 & 1,2 & 0,2 & 0, & 0,2 \\
\hline Сероводород & сл. & сл. & сл. & сл. & сл. & сл. & сл. & сл. & 8,5 & сл. \\
\hline
\end{tabular}

смол. Состав газа (табл. 2) показывает, что количество водорода было во всех опытах достаточным. Количество метана, этана и пропана увеличивается с повышением температуры гидрогенизации. При гидрогенизации в присутствии растворителя содержание метана доходит до $22 \%$, увеличивается также количество этана и пропана. В присутствии воды (в результате конверсии) образуются значительные количества углекислого газа.

При рассмотрении хроматограмм парафинов выяснилось, что на них при определенной длине цепи выделяются гомологи с «нечетным» числом атомов углерода. Отношение «нечетных» гомологов к «четным» (коэффициент нечетности - KН) рассчитано по формуле [3] (табл. 3). 
Таблица 3 Для парафинов $\mathrm{C}_{11}-\mathrm{C}_{19}$ гидро-

Коэффициенты нечетности (КН) парафинов, выделенных из продуктов деструкции болгарского сланца

\begin{tabular}{l|l|l}
\hline Условия деструкции & Парафины & КН \\
\hline
\end{tabular}

Полукоксование

$$
\begin{array}{ll}
\mathrm{C}_{11}-\mathrm{C}_{19} & 1,06 \\
\mathrm{C}_{11}-\mathrm{C}_{29} & 1,10 \\
\mathrm{C}_{11}-\mathrm{C}_{19} & 1,11 \\
\mathrm{C}_{11}-\mathrm{C}_{21} & 1,25 \\
\mathrm{C}_{11}-\mathrm{C}_{19} & 1,16
\end{array}
$$

Конверсия водой

Ожижение в присутствии циклогексана

Гидрогенизация формиатами

генизатов и смолы полукоксования значение $\mathrm{KH}$ низкое, но выше единицы. При более длинных цепях повышение $\mathrm{KH}$ наблюдается только в смоле полукоксования. $\mathrm{KH}$ является своеобразным показателем сохранности исходного биологического вещества (жирных кислот) формирования керогена. При керогенообразовании кислоты, имеющие четное число углеродных атомов, декарбоксилируются [4]. При деструкции образовавшиеся «нечетные» цепи отщепляются в виде соответствующих парафинов [5]. Повышенный $\mathrm{KH}$ парафинов гидрогенизата и смолы полукоксования показывает, что при диагенезе ОВ глубоких процессов превращения (в том числе и бактериальных) не происходило и что при деструкции керогена не было вторичных реакций, поэтому сохранились исходные структуры биологического вещества. В целом КН парафинов гидрогенизатов выше, чем парафинов полукоксования. Из этого можно делать вывод, что при гидрогенизации $\beta$-отщепление проходит в меньшей степени, чем при термической деструкции, в ином случае образующиеся гидрированные «четные» цепи понизили бы КН.

При термической деструкции образуются также олефины - главным образом $н$-алкены-1, общее количество которых составляет половину от суммарного количества парафинов. Выход низкокипящих олефинов $\mathrm{C}_{9}-\mathrm{C}_{10}$ относительно высок - в таких же количествах, как соответствующих парафинов, но с удлинением углеродной цепи их концентрация уменьшается. Объясняется это тем, что в начале деструкции отщепляются преимущественно длинные цепи, при этом исх́одное вещество обогащается водородом, который переходит в летучие продукты с образованием парафинов. В последних стадиях деструкции кероген уже ароматизирован, и связанными с ним остаются более короткие цепи, которые в результате $\beta$-разрыва отщепляются в виде олефинов, содержащих на один атом углерода меньше, чем исходные цепи в керогене [5]. Так как исходные цепи «нечетные», при термической деструкции следует ожидать образования «четных» олефинов, что действительно и наблюдается: концентрация 1-олефинов $\mathrm{C}_{10}, \mathrm{C}_{12}$ и $\mathrm{C}_{14}$ выше, чем соседних гомологов. При каталитическом гидрировании образования олефинов не наблюдалось, следовательно, насыщение олефинов в присутствии катализатора проходит очень легко. При конверсии водой и гидрогенизации формиатами олефины образуются лишь в следовых количествах.

\section{Выводы}

1. Несмотря на одинаковый элементный состав с эстонским сланцемкукерситом, болгарский сланец деструктивному гидрированию подвергается гораздо труднее, выходы жидкого гидрогенизата при этом относительно низкие.

2. Самые характерные структурные элементы керогена болгарского 
сланца месторождения «Мандра» - длинные неразветвленные углеродные цепи, содержащие от 10 до 37 атомов углерода.

3. В смоле полукоксования и продуктах гидрогенизации формиатим, термического растворения и конверсии водой обнаружены длинноцепочечные $H$-алканоны от $\mathrm{C}_{9}$ до $\mathrm{C}_{23}$.

4. Полученные данные свидетельствуют о важной роли терригенного материала в процессе образования сланца; известно, что биологическими продуцентами углеродных цепей, содержащих до 33 атомов углерода, являются наземные растения, в частности их восковая часть.

5. Повышенный КН гидрогенизатов и смолы полукоксования показывает, что при диагенезе ОВ сланца не происходило глубоких процессов превращения и что при деструкции керогена вторичные реакции не протекали, поэтому исходные структуры биологического вещества сохранились.

\section{Л И ТЕР А Т Р А}

1. K 1 esment, I. Application of chromatographic methods in biogeochemical investigations. - J. Chromatogr., 1974, v. 91, p. 705-713.

2. Коняшина Р. А., Кричко А. А., Никифорова Г. С., Пахомов В. П. Определение состава водородсодержащего газа методом газовой хроматографин. - Химия тв. топлива, 1970 , № 4, с. 135-138.

3. B ray, E. E., Evans, E. D. Distribution of $n$-parafifins as a clue to recognition of source beds. - Geochim. Cosmochim. Acta, 1961, v. 22, N 1, p. 2-9.

4. Кл ес ме н т И. Р. Алифатические структуры в керогене горючих сланцев. - В кн.: Исследование органического вещества современных и ископаемых осадков. М., 1976 , c. $187-195$.

5. Клесмент И. Р. Роль жирных кислот при образовании некоторых сапропелитов. - В кн.: Органическое вещество современных и ископаемых осадков. М., 1974 , c. $122-129$.

$\begin{array}{cc}\text { Ннститут химии } & \text { Поступила в редакцию } \\ \text { Академии наук Эстонской ССР } & 26 / \mathrm{X} 1978\end{array}$

Lia NAPPA, I. KLESMENT, N. VINK, K. KAILAS

\section{MANDRA LEIUKOHA POLEVKIVI ORGAANILISE AINE UURIMINE MADALATEMPERATUURILISE DESTRUKTIIVSE HODROGENISATSIOONI TEEL}

Artiklis kirjeldatud uuringute (poolkoksistamine, termiline lahustamine, veega konverteerimine, hüdrogeniseerimine temperatuuril $330-420^{\circ} \mathrm{C}$ ) põhjal on esitatud järeldus, et Bulgaaria Mandra leiukoha pốlevkivi kerogeeni iseloomustavad pikad hargnemata süsinikuahelad $\mathrm{C}_{10}-\mathrm{C}_{37}$.

Lia NAPPA, I. KLESMENT, N. VINK, K. KAILAS

\section{INVESTIGATION OF THE ORGANIC MATTER OF THE MANDRA OIL SHALE BY LOW-TEMPERATURE DESTRUCTIVE HYDROGENIZATION}

The results of catalytic hydrogenization at temperatures $330-420^{\circ} \mathrm{C}$ under hydrogen pressure are described. For comparison semicoking, thermal solubilization, conversion with water and non-catalytic hydrogenization with hydrogen obtained by the decomposition of sodium formate are carried out. The most characteristic structural elements of the organic matter of Bulgarian oil shale are long straight carbon chains containing $10-37$ carbon atoms. 